\title{
THE SCIENTIST AS AN ANALOGICAL REASONER: A CRITIQUE OF THE METAPHOR THEORY OF INNOVATION
}

\author{
KARIN D. KNORR \\ University of Pennsylvania
}

\section{Summary}

Recent, well-known explorations of the role of models in science suggest a theory of scientific innovation which links innovation to a creative extension of knowledge brought about by the invokation of a metaphor. At the same time, concrete evidence about actual procedures of scientific investigation have for the first time become available from anthropological observation studies of scientific laboratories. This paper draws upon one year of observations done in 1976-77 in a group working on chemical, microbiological, toxicological and technological aspects of plant proteins and plant protein generation at a research institute employing more than 300 scientists in Berkeley, $\mathrm{Ca}$. and upon interviews done with scientists of various other groups at the same institute. The paper attempts to reconsider the role of metaphor in the light of the observer's account of the research process in the laboratory, and in the light of the scientists' accounts of research efforts they considered innovative. Both the scientists' and the observer's account suggest that reference to metaphor needs to be extended to include, in accordance with some earlier conceptual investigations, the more general phenomenon of analogical reasoning. At the same time they suggest that the metaphor- or analogytheory needs to be restricted in its claim to account for innovation, and that innovation must be linked to the active constructions of the process of production and reproduction of research.

\section{The Metaphor-Theory of Innovation}

It is probably no exaggeration to say that the question of scientific innovation 
has in the past received most attention in a host of issues relevant to the process of scientific investigation: the 'context of discovery' is considered significant mainly in as far as it produces scientific innovation and much ignored with respect to anything else. The collection of papers brought together in this volume illustrates the narrow-mindedness of such a conception. Yet the data we have now on the process of scientific investigation also allow us to reconsider the question of scientific innovation. In recent years, the most relevant and illuminative account of scientific innovation has been given by the metaphor-theory of innovation. In the following, I will discuss the metaphor-theory of innovation in the light of material which comes from the direct observation of and talk to scientists at work. Rather than to start from a product which is a declared scientific innovation and to search for its explanation, we will look at the process of production from which 'scientific innovation' emerges. In contrast to the question of discovery acceptance treated in Section 2, the focus here will be on discovery accounts which are given by the scientists as well as by the observer of scientific investigation. While other papers in this section emphasize the cognitive-perceptual basis of such accounts, their formal organization, or the situational logic of the underlying process, my interest here is in the dynamics of research as implied by what we will hear. The question of scientific innovation has mainly been conceived of as a question of the origin of ideas. It is the purpose of this paper to link scientific innovation to the process of research production. I will begin with a discussion of the metaphor theory of innovation.

Imagine a bag-lunch in a small laboratory connected with a scientist's office room. Two scientists chat about the progress of the protein work, and one takes his protein samples from the shelf and shows them to the other. The first scientist had just told his colleague that he did not know how to account for the different volumes they had obtained in a series of experiments on proteins exposed to different degrees of temperature. The other says that the hardness of the protein particles might be a relevant factor there, and continues to elaborate about particle size and particle behaviour. The first scientist turns the 'worst'-looking sample in his hands as if closely inspecting it: "Well, this protein really looks just like sand!" he responds.

Similes such as the above have found some attention in recent literature because of the role which is attributed to them in scientific innovation. "If the protein looks like sand" the scientist in charge of the samples went on to 
reason, "it must be denatured. If it is denatured, it's effect will be to dilute the samples, and nothing else. Thus if it does dilute the samples just like sand would, we will have the proof of the 'dilution-theory', in which everybody seems to believe. But if it does not have the same effect as sand, I can finally disprove this crap of dilution, and propose my own interpretation"(1). Three hours later the scientist had dropped whatever he had been doing originally; he had gone to the storage room and found some chemically pure sand; he had set up a 'quick and dirty' experiment designed to compare the behaviour of sand- and protein-samples under heat treatment; and he had almost ruined a blender in which the particles of the sand left unremovable scratches. But he had also built a strong argument for his interpretation, since the behaviour of the sand-diluted samples turned out to be indeed significantly different from that of the protein-diluted samples. To be sure, the results were preliminary because of the quick and dirty character of the test. Yet the comparison between protein and sand eventually led to a new theory of protein additives as well as to an elaborate investigation of protein particle behaviour.

The metaphor theory of innovation assumes that figurative comparisons such as the one between protein and sand are the very source of conceptual innovation (2). Through metaphor, two phenomena or concepts which are usually not associated with each other are suddenly perceived to have some kind of correspondence. Through this intimation of similarity between hitherto unrelated con/cepts or phenomena the systems of knowledge and belief associated with each conceptual object can be brought to bear upon the other conceptual object. This is the source of creative extension of knowledge. The example above is slightly more complicated since the similarity invoked between protein and sand suggested an experimental way to expose a presumed underlying un-similarity between the respective particles with respect to the property of denaturation. Yet it did so by bringing to bear knowledge about the properties of one phenomenon (sand) upon another phenomenon (protein) whose properties were up to investigation. In the literary use of metaphor, the same effect is achieved through the systems of associations which we combine with a conceptual object. In Dante's "hell is a lake of ice" for example (3), the images and ideas we combine with a lake of ice are a source of creative extension of the picture we may have had of hell up to reading the metaphor. This creative extension of ideas is not limited to the conceptual object under consideration; in principle, the image invoked to 
illuminate this object will also change through an extension of ideas associated with the object. Not only does hell become more like a lake of ice as a result of the similarity classification, but a lake of ice does also become more like hell. Conceptual interaction as a basically symmetric relationship is considered to be the core of the metaphor-theory of innovation.

However, conceptual interaction and symmetry of influence do not only characterize metaphoric classifications. They are part of analogical reasoning in general, or of similarity classifications. Analogical reasoning is based upon a logic of resemblance in which the notion of similarity is described as logically basic and primitive: basic in the sense that it is presupposed from the very beginnings of language learning onwards, and primitive in the sense of its apparent irreducibility to analytic criteria (4). It appears that metaphoric classification can best be differentiated from other kinds of analogical reasoning by the degree of distance or independence between the two conceptual systems brought together through similarity classification. In the limiting case of 'primary recognition' (5), we can no longer distinguish between the two conceptual systems. Primary recognition refers to our seeing something as something, that is to the recognition of differential segments of our natural and social environment by identifying them in our natural language or in a professional idiolect. Our scientist's remark "the stuff has gone white" when he looked at his protein samples is an example from the laboratory in which a given stimulus is identified as an instance of a certain kind. Note that the definition of primary recognition in terms of similarity gives credit to the 'theory-ladenness' (Feyerabend) of observation (6).

A second form of similarity classification is involved when we 'interpret' a situation or when we 'account' for a phenomenon. For example, the scientist might have said, when he saw the white colour of the samples, that "the protein was precipitated", for it was this interpretation of his recognition that the stuff had gone white upon which he based his further procedures. When we determine that a given situation fits into an interpretation, we are in a sense determining that the current situation is analogous to those situations from which the interpretation was originally derived. In other words, the original situation serves as a kind of paradigm case against which the new situation is matched when we interpret it. More important here, we are apt to make inferences about unobserved aspects of the situation for which we account from the accounting situation. This making of inferences is, in 
principle, symmetric, since the contexts of association of both the interpreting and the interpreted situation can potentially influence each other. In the laboratory for example, this can be seen when the outcome of a recalcitrant experiment suggests a modification of the covering interpretation which in itself had created the expectations in terms of which the experiment had been conducted. What is important here is that the classifications involved are intended and used in a literal way, which means that the observed situation tends to get absorbed in the similarity class applied to it. Despite this tendency toward assimilation, the classified situation retains independency as long as it is independently describable, and so does the interpretation. This becomes obvious when an interpretation is modified, revised or extended. In the above example, the protein was found to be not only precipitated, but also otherwise affected by the means of precipitation used. When no decision is reached between different kinds of interpretation, interpretation is impending, but sustained for the time being. Given the basic independence between an interpretation and the situation it classifies, we can also say that this kind of similarity classification involves a greater distance than primary recognition.

Metaphor can now be seen as the form of similarity classification which involves the greatest distance between the conceptual objects classified as similar, in the sense that it would be absurd or false to take the conjunction proposed literally. Primary recognition makes an occurrence recognizable as something. Interpretations classify an occurrence as 'really' an instance of something else. Metaphors classify occurrences as similar, but really not the same. In the example cited in the beginning, protein was obviously not considered really to be sand. For the time being, we should add, since a metaphor can become a literal interpretation over time, or for some specific reasons. According to Hesse (7), even primary recognitions do not provide "a stable and independent list of primitive observation predicates". Nor do, of course, interpretative or metaphoric classifications establish a similarity relationship which could not be de-established or changed with respect to the degree of distance it originally implied. Needless to say, much of the scientists' work goes into demonstrating why and to what degree some object is or is not an instance of a certain kind. Similarity relationships are not just perceived; nor are they hidden to be discovered once and for all as seems to be suggested by Koestler (8). The scientists' suddenly recognized similarities include an element of decision and of persuasion, and consequently also of 
change (9). In that sense, the similarities which underly a metaphor or an analogy are complex rather than primitive, fragile and temporary rather than basic and stable.

Because of their figurative character, metaphors show this perhaps more clearly than literal interpretations. But the important point about metaphor as exemplified in the beginning was not the figurative character of the similarity relationship it established between the objects brought together, but the conceptual interaction and subsequent extension of knowledge to which it led. This conceptual interaction, however, is not limited to the use of metaphor, as indicated before. Rather, conceptual interaction appears to be a routine feature of 'displacements of concepts' in general (10). Conceptual objects are regularly transfered to instances beyond their original range of application. They are displaced to contexts which differ from the situation of their established use. They are extended to problems which are clearly distinguished from those which they have previously solved. It is this difference of some sort which is reflected in distinctive descriptions of the two objects brought together, and it is this difference which is bridged by analogical reasoning. Conceptual interaction emerges from the different universes of knowledge or belief associated with the distinctive descriptions brought together by a presumed similarity. While an analogy needs to be made in order to allow for conceptual interaction, it need not be made in a figurative sense: when two situations or problems become seen to be really similar the knowledge we have of one will be extended to the other, just as it will be in the case of a figurative similarity. In the process of extension, this knowledge regularly becomes modified according to the particularities of the new situation, and the result of this process will transform the interpretation of the original situation.

\section{The Scientists' Accounts of Innovation}

The argument of the last paragraph suggests that the social scientist's account of innovation in terms of metaphor must be broadened to refer to analogical reasoning in general, since conceptual interaction and the extension of knowledge it breeds cannot be limited to figurative similarity relationships. The argument here is that the scientists' own accounts of innovation display such a broadened perspective, since they link innovation to the making of analogies 
in a much more general sense than postulated by the metaphor-account of innovation. When scientists were asked to tell the story of the origin of an idea or of a research effort which they considered to be innovative, they regularly displayed themselves as analogical reasoners who built their 'innovative' research upon a perceived similarity between hitherto unrelated problem contexts. Let us consider the story of a biochemist who told me about his work on the isolation of hormones in a mold, a line of research which he traced back to the idea of a colleague that steroids might be involved in the transformation processes which the mold undergoes. The colleague, a biologist $(B)$, appeared to be attracted by the problem of the slime mold

She is not the only one who is interested in this mold. Many biologists like this mold because it is a model of differentiation. It changes from an animal to a plant as the result of some hormone stimulation.

$B$ was aware of the fact that steroids are involved in the reproduction of many forms of life. When she became pregnant, it 'occurred' to her that the hormone which stimulated the transformation of the mold and which was unknown at the time might be a steroid

Her original discovery was that when she was pregnant, she used some of her urine (which contains steroids) to stimulate the mold to undergo this conversion. - The idea that steroids are involved in reproduction even in the lowliest forms of life is not new ... although most biologists still don't accept it. Anyhow, she uh - tried some, and it worked. I mean what happens is very spectacular. These bugs are like amoeba, they crawl around on a plate of agar, and one of them will make a hormone which they call a (inaudible), but the nature of which was unknown at that time. And, when one creature makes this hormone the other creatures congregate. Or collect around this individual. In other words, this substance acts as an attractant. And after they all get together, they undergo this phenomenal transformation from ameboid animal-like creatures to a regular mold, you know ...

In the laboratory, the isolation of the hormone became complicated by the fact that the attempts to stimulate the mold with pregnancy urine did not work out. According to the biochemist

- it was not a real effect. No one could ever repeat(it). But she had a good hunch that steroids were involved and she had the wrong observations.

Consequently, the biochemist turned to a more direct way of trying to isolate the hormone 
So anyhow, she brought this pregnancy urine, and I was working on uh steroid hormones in urine among other things and I knew how to isolate them and I used my methods, and what I got out her urine didn't work at all. And I have had some hormones that I had in the lab in pure form and they didn't work either. And then I had the idea of going to the mold directly. During that time that this aggregation, this congregation of individuals takes place there must be more of this hormone present. So I thought that if we, uh, go to this mold directly and then isolate from it the fraction that is biologically active, that causes this attraction, we will find out what this hormone is. So we did this, and using methods that I had developed over the years . . . you have to use fractionation methods, you know. And in deciding which fraction to keep and which one to throw away you have to have a bioassay method. So - after your separation you take the individual fractions and test them and see whether they cause aggregation. And we did that together, and low and behold, one of the fractions had ... the ability to cause aggregation. And this happened to be a steroid, and since then some other steroids have been isolated from all kinds of mold. They also have sex hormone activity. They are not related to the sex hormone that women have in pregnancy. They are steroids, but they are in a different class of steroids.

The similarity which underlies the biologist's attempt to stimulate the mold with the help of pregnancy urine is that between the transformation of the mold and reproduction in other forms of life. Since the latter often involves steroids, the biologist had "the good hunch" that steroids would be involved in the transformation of the mold too. In the scientist's account, the idea that the unknown hormones could very well be steroids is based upon the establishment of a similarity between two contexts and the transfer of one element from one context to another.

The following story shows a similar pattern. It was told by the same biochemist and involves the group which he supervised

This happened during a time when we already had a small group. And I was interested in finding out how steroids are synthesized in plants. These are plant steroids, and there are all kinds of theories on how they are made and nobody really knew. So we were working away, and doing pretty pedestrian stuff, until one of my colleagues found ... a lot of radioactivity incorporated in a particular fraction which was present in such minute quantities that we couldn't identify the material. But talking among ourselves we came to the conclusion that it could be cholesterol. There was another man in the group who was working on unrelated problems and had a similar observation ... And then they pooled their resources and, uh, of course mine too and we together came up with the conclusion that this was cholesterol. And this opened up a whole series of experiments which culminated in the fact that cholesterol which was up to then considered to be a real animal product that wasn't even present in plants is actually the substance from which all plants steroids are made. And this is, uh, very significant, we can now trace the biosynthesis of plant steroids very easily by administering radioactive cholesterol 
and seeing what transformations it has to go through before it becomes one of those many many steroids that occur in plants.

When I asked him how they had arrived at the respective conclusion the scientist said

You see, I had been working on people up to then. And, although it wasn't very clear at the time I started it, it became increasingly evident, during the time - from both my own work and that of other people, that cholesterol in animals and in people is the key substance from which all the other steroids are made.

But it was known at the time that "plants do not contain cholesterol". So there was the discovery by my colleagues that the radioactivity accumulated in a certain fraction ... The link (between the observation of accumulated radioactivity and the idea that this was cholesterol) was that in animals that's what you would expect. That's what we as well as other people had previously observed. But that the same thing could happen in plants was completely unexpected, because until that time nobody knew that plants even contain cholesterol. (emphasis added)

The observation of accumulated radioactivity in a certain fraction of the plant material together with other aspects of the problem and procedure provided a context similar enough to that of cholesterol-formation in animals to suggest the 'idea' that cholesterol was formed in plants too, despite of the ruling contrary opinion (the attractiveness of the idea derived at least partly from its being in opposition to established beliefs). Thus we have again a report of a transposition of one element from one context to another which displayed itself as sufficiently similar to the original context to suggest and warrant the transfer. The examples above can also be considered from the point of view of the result of the transfer: in both cases, the scientists found an explanation for a phenomenon by assimilating it to known phenomena, that is to the operation of steroids in reproduction and of cholesterol in animals. Other stories of the origin of research results which the scientists held to be innovative did not invoke the context of explanation, yet they implied the same pattern of analogical transfer.

In the following account which is a summary of various comments a scientist had made during the period of observation, an enzymatic procedure is the element transposed. The scientist $(K)$ who worked on plant proteins had found a certain plant protein to contain an expectably high amount of toxic solanine. During the later part of my observations, he more or less intentionally ignored the problem, as it had no immediate bearing on the 
research underway or on projected publications. He remained bothered by it, however, and occasionally talked about the need to eliminate or reduce the solanine. At one point in time, he wondered whether he could not make the elimination of solanine a byproduct of some other, more pressing experiments

He discussed his plan with a colleague $(H)$ who had worked on solanine for many years. $H$ felt that the method showed no promise of success, but mentioned that his laboratory had recently been successful in eliminating a similar toxic compound from another plant by using an enzymatic procedure, a work which was as yet unpublished.

$K$ immediately picked up on the 'idea' to use $H$ 's enzymatic procedure to eliminate the solanine from his proteins

"I think I have the advantage of being the only one who got the message (about the existence and the success of $H$ 's enzymatic procedure), and the only one to understand its implications" (for the elimination of solanine). Both scientists deemed it to be highly probable that some equivalent enzymatic procedure would work in the case of $K$ 's plant material too. $H$ was 'not interested' to do the necessary research himself. He was 'too settled on chromatography and his own projects' according to his colleague. For the latter, $H$ 's disinterest appeared as an excellent opportunity not only 'to solve the problem', but also to distinguish himself by exploiting an idea which would otherwise not be used.

Note that when $K$ heard about the enzymatic procedure, he immediately responded to it as the key to solving the problem of solanine elimination, despite of the fact that the procedure had been established for a different plant and a different toxic compound. The contextual similarities between the problem of solanine elimination in $K$ 's proteins and the problem for which the procedure had worked out originally were appealing enough to suggest the transfer of the 'idea' of such a method. Naturally, what we called 'transfer' involved modification and adaptation, for example working with different enzymes. It thus required an actual transformation of the procedure involved.

There are many more examples of this kind which I encountered during the period of observation

One of the scientists involved in the plant protein generation got a report from the head of his group who had just returned from a visit of several research groups in industrial and nonindustrial settings in different European and American countries. The report 
mentioned in passing, as the scientist told me, that "the people at NN try to enrich soft drinks with protein and that they found that the protein colour of the samples used became lighter when citric acid was applied in the process". The samples had been sent to them by the head of the group for the respective protein-additive tests.

Since the scientist was interested in obtaining a protein powder which was as light as possible, the idea of using citric acid as a coagulant which would not pollute the proteins appeared promising enough to be tried out immediately in a series of experiments.

Again, both contexts resembled each other to a sufficient degree to warrant the transfer of the procedure, although they involved different proteins, different goals, and a variety of other differences. At an earlier point in time, a similar transfer of a method had given rise to a whole new line of research

The scientist mentioned above was looking for a way to generate large amounts of protein needed for bioassay tests which involved feeding the protein to rats. At one point in time, he happened to read a paper in which the use of ferric chloride was reported as an effective means of precipitation when removing protein from waste water. In general, precipitation of protein which is an important step in protein recovery is done by using heat coagulation methods which involve high temperatures and result in a strongly denatured protein.

In the context of an energy shortage, the use of ferric chloride instead of heat coagulation appeared as an excellent alternative for protein generation in general: because of the low protein content of the source material, the energy consumption associated with heat coagulation was enormous. Thus by transferring the use of ferric chloride from the context of waste water cleaning to that of protein generation from plants the scientist had solved the problem of generating a sufficiently large amount of protein for the intended bioassay tests. At the same time, he had initiated a new line of research which was based upon the appeal of a low-energy method resulting in a higher quality protein at a time of a generally recognized energy shortage and of an increased quality awareness.

While the last examples illustrate the transfer of a method or procedure from one context to another, the following account refers to the transfer of a kind of solution. The example comes from the food engineering group of the institute in which the observations were done. The group leader told me the story of the origin of one of the group's current research efforts which he considered innovative

As described by the research leader, in sweetcorn processing "corn is cut with a knife, (and in) doing so you make a tremendous amount of effluent during the washing step and you loose all of the flavour of the product". He said that "this is something everybody is aware of (who has) worked in the food industry and seen corn processing plants".

The scientists started to look at this process "as a group upstairs said you guys should be working on a big project". The head whose background is in chemical engineering 
continued: "So we said OK, we will show you that we can do a big project... (and) we formed a group and started to look at ways of changing the process completely ... It is intuitively obvious that you have to keep the corn kernel intact, because if you break it open everything is leached out. So we immediately had to go to a process that stripped the kernel off the cob without damaging the body of the kernel. And ... we did go to the literature and found the patents, 1600 or 1700 . People had frozen the cob and broken off the kernel, (there were) a number of cutting techniques, etc $\ldots R$ came up with the idea of splitting the cob in half and then wiping the kernels off with a belt. Well, they started out with a belt like this and they went through 800 different types of belts and they finally ended up with a belt made out of (unaudible). So we now have a technology at least in its infancy that can produce unit kernels. But right after the start of the project, after the first season we realized that the corn cob itself was designed to frustrate the removal of kernels by a rolling or plucking action as we called it.

The scientist was well familiar with the type of solution that had played a key role in mechanical harvesting problems. This familiarity accounts for the transfer of the solution

In the tomato industry, mechanical harvesting with tomatoes was successful only because they were able to get a variety that could be mechanically harvested. And the thing that occurred to me to do was to check around - to find out whether there (was) a corn that is loosely held and that is suitable for mechanical ... stripping as we were talking about. I made a few phone calls around the country to people I had worked with in the past who knew something about sweetcorn. And in two or three calls they directed me to one of the key corn breeders in the country.

So it turns out that this fellow had been breeding corn for 25 years to get a, ... a variety which was very loosely held. It was for fresh market consumption. But it was a sweetcorn without the little pieces of tissue at the base of the kernels which get stuck in your teeth. And he had bred corn with two rows, four rows, square cobs. And he pulls out (this corn) and shows (it to) me, and it is the type of thing when it is at the proper maturity for processing, the kernels roll right out. (He was just at the point) where he had increased the seed to where he could go to Florida that winter and grow the first handful for commercial testing. So we got the first handful and this year we got the first pound of the seed. We have been able to evaluate it, and indeed it is the type of raw material that will allow ... (mechanical) processing.

There is no need to quote further accounts of innovative research in order to illustrate the kind of analogical reasoning outlined in the beginning. It will also be clear that there is an extension of knowledge based upon interaction in the sense of a basically symmetric influence of the instances brought together in similarity classification. For example, not only did the familiar operation of steroids in the reproduction of certain forms of life suggest that steroids might play a role in the unclear situation of the transformation of the 
mold, but the knowledge of the hormone itself changed too. It changed to include a series of steroids which were subsequently isolated from all kinds of molds, by the fact that the steroids present in human pregnancy turned out to be not identical with the steriods of the slime mold, and by a variety of other results which emerged from the research. Similar changes occurred with regard to the substance of cholesterol, with respect to the enzymatic procedure proposed to remove toxic compounds from certain plants, or with respect to the bleaching and precipitating effect of citric acid. From the accounts given it will, however, also be clear that these transformations did not just result from conceptual interaction; instead, they resulted from a process of production and reproduction.

\section{The Conservatism of Scientific Innovation}

Usually, the beginning of a piece of research is when something strikes a spark on one's imagination: something one does not know seems a particularly fascinating thing to try and find out. Partly, the thing itself seems important and fascinating in its own right, partly, one has intimations that one can find it out. That is where the spark comes in - the intimation that one actually can find it out gives one a particular thrill that is irresistible. There is a flash, and as with love one knows that one is in it.

Let us look now at the scientists' stories of innovation from a different angle. Consider these stories as accounts of happenings in the process of research production. What does the happening of an 'idea' based upon an analogical influence mean in this process? The first thing to note is that the 'ideas' which mark an analogical transfer or the occurrence of a metaphor have the character of solutions. We have said that the very significance of analogical reasoning in this context is that it brings to bear knowledge from a familiar, well-know, clear case upon an unclear, less familiar, problematic situation. Thus, the analogy relation relevant here mobilizes a resource which creates an opportunity for success: since the knowledge mobilized by the analogy or metaphor has worked in a similar context, it holds the promis that it can be made to work, given appropriate modifications, in the new situation. It is precisely this promise of success to which Albert Woods refers when he says, in William Cooper's tale of an experimental chemist quoted above (11), that it is the intimation that one actually can find it out which gives one a particular thrill that is irresistible. And it is this promise of success associated 
with the 'unsatisfied capacity' (12) of the scientists' analogical transfers which lurks behind the scientists' talk of 'the interest' of an idea.

A second point to note refers to the difference between the 'ideas' of the laboratory and the hypotheses of the methodologists' vernacular. If the 'ideas' which mark an analogy relation are unrealized solutions holding promise of success, the research associated with these ideas assumes a peculiar post hoc quality, since the investigation is made after the solution has been hit upon. The conception of such ideas as unrealized solutions contrasts sharply with the notion that these ideas are, logically speaking, hypotheses, that is ex ante conjectures about a phenomenon subjected to test in the research process. Hypotheses are tried against data, with the ultimate goal that they stand up as either true or false, or one of their weaker substitutes such as confirmed/ disconfirmed or tenable/untenable. They require the data which they take to be collected through research to be independent arbiters of the propositions they contain. With ideas that are unrealized solutions mobilized by an analogy relation no such independence can be assumed. Unrealized solutions are not tried against data;instead they are made to work by scientists who are actively engaged in constructing the results anticipated by the solution. They are made to work differently by different scientists depending on practical circumstances, and they are made to work with different degrees of success. The suggestion here is not that to realize a solution is a simple, smooth or short undertaking. The suggestion is rather that to make a solution work rises other questions than those which are specified by the language of hypothesistesting. The standards against which the ideas of the laboratory are measured do not refer us to the world of theoretical interpretation. Instead they refer us to a world of instrumentation and collaboration, of chances of publication and of the investments at stake. In short, they refer us to a process of production whose products are specified by what can be done. Unrealized solutions do not eliminate problems, search processes or outright failures from the process of research. But they turn the open ground of unresolved research problems into the closed program of a production line. It is the unrealized solutions, not the problems which take the lead in this process of production. It is the power associated with unrealized capacities which drives the research process forward, and it drives it in whatever direction the capacities lie.

The scientists' tendency to respond to 'ideas' as 'solutions' and the post hoc character of the investigations initiated by these solutions refers us to a 
third-point to mention here, the scientists' 'risks'. As suggested (13), solutions are problem translations which are themselves problematic in that they require further problems to be solved. To realize the idea that steroids are involved in the transformation of the slime mold posed the problem of isolating the steroids, and of identifying the right kind of steroids. A scientist's hunch as to how such subsequent problems can be solved is not always correct, as we have seen in the case of the slime mold. When attempting to realize a solution, the scientist faces a certain risk. Furthermore, problems may have to be attended to independent of whether an attractive or reasonably satisfactory solution is in sight. To paraphrase Albert Woods (14), scientists cannot always lay themselves open for something to strike a spark on them - they may have to strike a spark on it and to do so within a limited amount of time. This also implies a certain amount of risk of being unsuccessful. Scientists at the institute observed were well aware of these risks. When talking about a new idea, they displayed a full range of circumstantial reasoning within which these risks appeared to be evaluated. The appeal of an idea were the chances of convincing the research leader of it, of recruiting laboratory assistants, of finding the necessary equipment, of being the first to publish, of having time to do the work, etc. As a chemist told me in the context of his story of innovative ideas he had produced:

- You try to discriminate. You can get one idea a day, or ... (in) two days, or one a week, and you discriminate (in terms of) your time and your ability to use it. You know, we have idea files, either in your mind or on paper, but you can't spend a lot of your time on things you don't have the opportunity to perform, or to prove, or to verify. So you try to limit your interest to the idea in which you know you are going to be most productive as quickly as possible within the frame of facilities you got at your hands. (emphasis added)

A biochemist's version of this was as follows:

We always calculate our risks although we don't know how to calculate. It's just that feel, you know, and I am very good at this by now (through the) many years of experience. I can more or less tell what I should drop and what I should pick up. I think this is a problem with a lot of unsuccessful scientists, that they are not dumb, they just work on the wrong things ... Another thing is, if you are up against a terrific competition, there is no sense in struggling. (emphasis added)

"By now", he added, "I can gage these success factors, and my secret of 
success is that I work on things that aren't too unlikely to work out." The scientists I listened to were not only aware of the risks associated with their analogy-based 'ideas'. They displayed a concern with keeping these risks at a low level. We have said that the scientists' analogical transfers represent unrealized solutions which the scientists seem eager to exploit if local circumstances allow for it. When the scientists follow the lead of an unrealized solution, they do not foolishly committ themselves to a journey of unknown destination, of unknown arrival time, and of unknown chances of getting anywhere. Instead, they choose a path of known destination on which they have a good chance to arrive at their goal, and on which they have a good chance to arrive there first and fastest. This implies that there is no reason to believe that scientists are, by nature or by necessity, devoted to risk taking. To say that research is a high risk enterprize may reflect the feelings of those who finance research in order to get a very specific result, with no apparent success. It does not reflect the reasoning of the scientists in the laboratory. Scientists can built their success on many a 'solution', provided they have the opportunity to follow its lead and provided they can make it work. Consequently, many of their arguments focus on securing these opportunities, and on sorting the circumstances which will allow them "to be most productive as quickly as possible within the frame of facilities" they got at their hands, as we have heard above. Analogical transfers form a firm ground for controlled rather than uncontrolled risks, since they mobilize a solution which has been proven to work, albeit in another context.

The scientists' analogy-based innovations imply a conservative strategy in more than one sense. They imply that one starts from an unrealized solution rather than from an open problem, and that one follows the leads of ideas which hold promise of success rather than to expose oneself to unknown risks and uncertainties. Most generally speaking, they imply that the interest of an 'innovative idea' is not that it is new, but that it is old in the sense that it draws upon available knowledge as a source for producing knowledge. In this process, previous selections are extended to new areas rather than being invented, and they are thereby reproduced and solidified. Scientific "consensus" emerges from such processes of reproduction. The notion of scientific consensus is misleading in that it suggests some process of public opinion formation among scientists, a process which results in unanimous decisions about certain knowledge claims and which thereby transforms these claims 
into 'accepted' or 'rejected' knowledge. What we have instead are the practices of ongoing research within local research scenes in which certain selections get reproduced, and through reproduction are expanded, reinforced, and perhaps petrified to become the solid rock of what counts as true. In as far as analogy-based 'discovery' is a form of spatial expansion of previous selections to new territories it is part of 'consensus formation', or better of the process of solidification and petrification of knowledge. The 'discovery' of the role of steroids in the transformation of the slime mold and in plants as described by the scientists illustrate this process of solidifcation through expansion, as do the other stories of innovation presented above.

If practical reproduction characterizes this process, this also means that the hallmark of analogical extension of knowledge is not just 'conceptual' interaction. It is the mobilization of resources for making things work in the ongoing process of laboratory production, and the transformation of the selections transferred through this process of production. These resources are not just 'ideas'. As indicated before, they refer to available instruments and to source materials which can be obtained from colleagues. They refer to laboratory lines of action which have been effective or to scientists to be consulted. They suggest timings and quantifications, or composition formulae which have been successful. In short, they refer to the mobilization and instantiation of means of production. In the case of the slime mold, the idea that the hormones involved are steroids suggested an array of methods of isolation and a laboratory which had the instruments. It suggested a group of scientists 'interested' in the work and a journal in which to publish the results. It triggered the idea of using purified hormones and led, through laboratory work, to the result that the steroids involved were different from those found in pregnancy urine. In subsequent research, it resulted in the discovery of steroids in all kinds of molds, and in the identification and exploration of the characteristics of these kinds of steroids. Just as the analogies relevant here are not just 'ideas', so the 'conceptual interaction' is not just 'conceptual'. The new results initiated by the making of an analogy are not just derived from the associations invoked by a striking and unexpected similarity, as they are in the literary use of analogical reasoning. They are grounded in the transformations of knowledge which results from laboratory reproduction. The process is material, and it has material consequences. 


\section{Ethnotheories of Innovation or the Assumptions behind Accounts of Innovation}

You asked me where is the origin - I remember the origin of everything because it isn't something you simply drift into! (In research) you have a concept based on somebody else's work, you would be standing on somebody else's shoulder, you are putting two pieces of something else together. But when an idea comes, it comes. It's not something that develops from a series of routine investigations!

There are may be half a dozen developments that we have been involved in, and I think each one has its own origin. There is no pattern to the origin of ideas! (emphasis added)

So far we have looked at the logic of sciences' metaphor account of innovation, and we have seen that it needs to be extended to include a more general form of reasoning by analogy. We have heard the scientists stories of the origin of some of their research efforts, and we found analogy-based 'ideas' to be indeed pervasive in work the scientists considered innovative. We have been confronted with the social scientist's interpretation of the role of metaphor and analogical transfer in research production. And we have seen this analogical reasoning qualified as 'conservative' in the sense that it implies a reproduction and solidification of previous selections and the controlled risk of transformations which result from territorial extension rather than from invention. We will now return to metaphor and analogy as the core of a theory of innovation. To begin with, let us look at some of the ethnotheories the scientists themselves hold about innovation.

The above quoted statements come from a chemist who had made his reputation by developing a microbiological assay of proteins using the microorganism Tetrahymena pyriformis $W$. during the first minutes of an interview in which he described the origin of this research. In a nutshell, the theory of innovation contained in these statements is a version of the 'lightning' theory of creativity which claims that ideas hit and strike out of the blue rather than to emerge as the (logical) result of previous investigations. When the first half hour of the interview was completed, the scientist had woven two more theories of innovation into his account. He said for example,

$\ldots$ as far as the innovations are concerned I think it means ... perceiving what the state (of affairs) is and taking what in your mind is the next logical step ... May be that's what creativity is, the summation of everything and putting it together and get a new answer... It's a logical, a logical sequence of events which may not (look) so logical to 
someone else, and they end up with being "creative". But I think most of it is going down the path and exploring and prospecting the road as you go along. (emphasis added)

And he added, when he came to talk about the group's 'fortuitous' observation that there was an optimum where they had expected a linear decreasing relationship in an experiment on a physical effect of humidity

So this was an anomaly, right. So the trick in all this, in all these what I call, what you might call innovations is observing the anomaly - what is different about this set of characteristics. And I think if you characterize any of the accomplishments (of science) it says: you tried something, you did something, and you found an anomaly, and (you investigated) what was the reason for the anomaly. Investigate the anomaly! (emphasis added)

In addition to the lightning theory of innovation, we are exposed to a 'logical' theory of innovation in which a discovery appears as nothing more than a step in a logical series of events. And we are exposed to an 'anomaly' theory of innovation in which the occurrence of unexpected events and relationships breeds innovation. These ethnotheories of innovation appear to contradict each other, especially since they were promoted within the context of one and the same question by one and the same scientist. Yet there is no necessary contradiction. 'Ideas' can be triggered off by anomalies which require explanation. The occurrence of an 'innovative idea' is a hit-and-strike chance-event if one tries to predict it, and a step in a logical sequence of events if one reconstructs a research problem after the fact. The scientist selectively looked at a process from different starting points when he promoted his theories, and he paid attention to different aspects of this process. He also answered somewhat different questions in each of his theories of innovation.

Let us now consider the social scientist's theory of innovation by reference to metaphor or to analogy. It adds to the picture painted by the above ethnotheories in that it tells us something about how an 'idea' leads to a creative extension of knowledge, that is by mobilizing knowledge we have from a different context. Yet like the ethnotheories of innovation, it proceeds selectively. For example, it does not address the question of when an innovative idea tends to occur, a question answered by the anomaly theory of innovation. Nor does it consider the question of how an innovative idea relates to the immediately preceding research, a question addressed by the logical theory of innovation. More important, the metaphor-or analogy-account of innovation 
is based upon a series of assumptions which tend to obscure rather than to illuminate the process of practical research. A theory of innovation which draws upon metaphor and analogical transfer is streamlined in terms of a successful end-product of investigation which is clearly identified. It starts from the assumption that an innovation has been made which has a name and an author and which is located in time through publication or through participants' accounts. In other words, it assumes that the 'who', the 'when', and the 'what' of an 'innovation' or 'discovery' are settled or can be settled upon further inquiries, and it answers the question of 'how' by reference to conceptual interaction and extension of knowledge induced by the establishment of a similarity relationship. However, 'innovations' are embedded in a past and a future of constructive - and consequently also of destructive work. When we look at this process in sufficient detail, we see that questions of date and authorship are not settled by the sheer existence of a phenomenon called an innovation, nor do they seem to get settled through close empirical studies of the phenomenon. Instead, clearcut answers to these questions require decisions to be made about what is and what is not significant with a view to the end product of innovation. For example, in the process of investigation the person who invokes an analogy, the person(s) who work out the experiments and those who gain credit for the work are often not the same. In the example of the simile "this protein really looks just like sand" mentioned at the beginning of this paper, the similarity was invoked by: a scientist who had nothing to do with the respective research in the context of a chat between colleagues who belonged to different research units. Needless to say, the question of the authorship of an 'idea' is by no means settled among the scientists themselves. One need not go to disputes over priority in the published literature to see this illustrated. In the stories of 'their' innovations they told me, the scientists often shifted and blurred what they had to say about the origin of these innovations. For example, the biochemist who told me about the discovery of cholesterol in plants started out by saying "they (his colleagues) pooled their resources and, uh, of course mine too, and we together came up with the conclusion that this was cholesterol" only to end up by saying, some 15 minutes later, "in order to accept my idea that cholesterol is present in all plants ..."

Questions of authorship and of the timing of innovation are the established battlefield of historians of science, and as such they need not bother the 
theorist interested in the logic of conceptual interaction. To a degree they will bother the social scientist who observes a process of research. Is (s)he to credit the scientist who jokingly invoked a similarity or the one who linked the picture to a workable procedure? The post doc who performed the experiment but not the technicians and the research leaders? And what does (s)he count as the 'origin' apart from the question who was original? Why not the observation that pregnancy urine stimulates the transformation of the slime mold rather than the 'idea' that steroids might be involved in that transformation? Of course these questions are of analytic rather than of practical nature. In practice, the necessary decisions are routinely made in an ad hoc way, and they will differ over different purposes and observers. The metaphor or analogy theory of innovation does not specify which decision criteria it prefers in these cases. And the observer of laboratory research does not yet dispose of the integrating principle of an acknowledged and identified 'innovation' for which history can be reconstructed. This brings us to a second point about the assumptions implicit in the metaphor or analogy theory, and one which is relevant as long as this theory claims to be a theory of innovation. The metaphor- or analogy-theory of innovation aims at explaining the (conceptual) origin of innovation. As indicated before, it does so by starting from the successful endproducts of research, from those who get qualified as 'innovations'. Thus it presupposes innovation as a given, unproblematic phenomenon from which it jumps to an "origin" located in the conceptual sphere. We can also say that it identifies innovation with the conceptual occurrence of the invocation of an analogy or metaphor, since it ignores virtually completely the process of research production which lies between this invocation and a research product's acknowledgement (15) as an 'innovation'. We have seen that questions of timing and authorship refer us to this process, yet they are only part of the more general question of how a research result becomes an 'innovation'. It is hard to see how this question could be attacked without due consideration of the process of production and reproduction of research. It is this process through which the ideas of the laboratory are turned into 'innovations', and it is his process in which a theory of innovation will have to be grounded.

\section{A Metaphor- or Analogy-theory of Failure and Mistake}

To expound the thesis, let us suppose for a moment that we are not interested 
in a theory of scientific innovation, but in a theory of scientific failure and mistake. The laboratory provides ample examples of such failures. Indeed all we have to do is to take one of the stories of 'innovation' presented before and place it into an ever enlarging context of ongoing research which surrounds this innovation. We will end up with a kind of genealogy of failures which at one point looked like, or were for some time, successful innovations. For example, the transfer of ferric chloride as a means of protein precipitation cited before was embedded in a whole chain of similar 'ideas', all involving analogical transfer. Most of these 'ideas' were accompagnied by specific research efforts. If we choose an arbitrary cutting point and do not look into the prehistory of the research, the first such transfer involved phosphoric acid:

The method had just been published and had been documented to work in a biochemical context. It appeared particularly attractive since the main author of the method worked at the same institute as the scientist who said it could be the solution to his problem of protein generation. Access to the author of the method meant the opportunity of a quick transfer of know-how resulting in an easier process of adaptation. It could also mean collaboration, and hence access to equipment, material and laboratory-assistance pretrained for the purpose.

However, after a period of further exploration the scientist appeared to become less convinced of the method. The context in which the method had worked did not match the new situation. The scientist complained that the experiments needed to be done under nitrogen which was difficult in the large scale laboratory which had to be used since large quantities of protein were needed. Some paper found suggested that phosphoric acid would generate toxic side effects. For large quantities, the method could become expensive. Nevertheless, the method was pursued until the scientist who wanted the protein happened to read about ferric chloride and immediately qualified it as a much 'better idea'.

The 'discovery' of ferric chloride not only sealed the fate of phosphoric acid as a non-solution, it also marked a change in the research focus. As we have heard earlier, protein generation became a research topic in its own right which replaced the original interest of doing biological assay tests with rats, an interest for which the large amounts of protein were needed. Thus one of the major lines of the group's research became the development of methods of protein generation from the respective plants. Ferric chloride was made to work in subsequent experiments. The resulting proteins had a high nitrogensolubility, a property considered highly desirable.

Thus ferric chloride proved to be a success and remained so throughout 
the period of observation, as indicated by a quickly published paper dedicated to the promotion of the method. More specifically, it remained a success from the point of view of protein generation. This success was threatened, however, as long as the protein could not be adequately purified. Consequently, quite a bit of effort went into solidifying the success by attempting purification. One idea to achieve purification was suggested in a somewhat ad hoc way when, at the eve of a large scale experiment, it was found out that there was nothing left of the adsorbent agent needed in the laboratory, and moreover, that the 'storage room' had run out of it too.

Since the date of the experiments had been fixed and could not be changed, not enough time was left to order the chemicals. In the somewhat nervous discussions which followed, a colleague suggested an adsorbent which he had used in his own previous research on proteins, where it had worked. The scientists did not appear to be intrigued by the idea, expecting difficulties with removing the adsorbent agent from the proteins. Nevertheless once they got started, attempts to purify the protein with this adsorbent agent went on for several weeks and months.

At one point in time the results were described enthusiastically as "better than anything achieved so far", with an implicit reference to another group of the institute which was said to have failed 'for 25 years' to isolate and purify protein of similar properties from a different plant. However, this success was short lived: after they had looked at the results of chemical composition tests, the scientists qualified it as an artefact. Shortly afterward, the attempt to work with this adsorbent agent was abandoned altogether.

During the time when efforts to use this adsorbent agent were still under way, the scientists picked up the 'idea' of using citric acid from a travel report of the research leader, as mentioned before. As it turned out, citric acid could not only substitute for the use of the above adsorbent agent as an alternative method to change the disturbing properties of the proteins. It could also substitute for ferric chloride as a method of protein generation. The experiments were done in the fall of 1976, toward the end of my observations. They mark the beginning of the deconstruction of the success of ferric chloride. This deconstruction was not completed until about 18 months later, when some of the data on citric acid were finally analyzed and reported in a paper which shows the advantages of this alternative method over ferric chloride. Some such deconstruction had been anticipated when the scientists moved to using aluminium sulphate instead of ferric chloride, an 'idea' which 
came up in a discussion with a visitor from Israel who suggested that it had been used in the context of environmental research in his country. Since the resulting proteins had a lower nitrogen solubility and other less desirable properties than those obtained from ferric chloride, the method had been qualified as a failure, which did not prevent the scientists from publishing the results in a paper comparing several methods. At the time, the failure had strengthened rather than threatened ferric chloride.

Two other 'ideas' relating to protein generation have been pursued in the meantime. One involves the chemical modification of the protein molecule, a procedure which allows for the engineering of the properties of the proteins. This has the consequence of a potential deconstruction of all 'successful' methods above in the sense that the protein-properties generated by these methods are no longer decisive for their success or failure. Note that this potential deconstruction again did not hinder the scientists to promote citric acid as a successful coagulant through publication (the paper is currently submitted). The second 'idea' involves an enzymatic weakening and a subsequent mechanical destruction of the cell walls of certain molds in order to obtain the protein found in the cell juice. Since the mold can be generated in indefinite quantities from sources such as oil, the potential of this procedure implies a similar change in the fate of the use of ferric chloride, or its present substitute, citric acid.

The last two procedures are to new to determine their fate although there are indications that the chemical engineering of protein-properties will be abandoned again because of the hazards it involves (16). Let us adopt another arbitrary cutting point and consider the development of protein generation research up to the use of citric acid. As shown by the fragments of this process presented above, there is no need to go outside the laboratory to observe the demolishing and replacement of what previously was a successful innovation: the scientists themselves constantly engage in the deconstruction and transformation of their 'innovative' results. In addition, many of the ideas of the laboratory which appeal to the scientists as 'innovative' and 'promising' of success do not work out under given practical circumstances, or are abandoned before bing tried out experimentally. Our genealogy of methods of protein generation which starts with the projected use of phosphoric acid and continues with ferric chloride and its ramifications to the use of aluminium sulphite and citric acid includes both kinds of failures. All methods involve at 
some origin marked by the scientists analogical transfers or a 'displacement' of knowledge from one context to another. So why not propose a theory which traces the origin of scientific failure and mistake back to the occurrence of analogical reasoning?

The point here is simple but consequential. Analogical transfers of 'ideas' as well as metaphors are routine features of scientific as well as everyday reasoning. They occur not only in the case of innovative success, but also in the case of 'blind alleys', 'degenerative problemshifts', or simple failures to make something work. Thus, a theory of innovation which limits itself to accounting for innovation in terms of conceptual interaction induced by analogy relations must recognize that it is at the same time a theory of failure and mistake. It does not discriminate between the differential success analogy based 'ideas' encounter in the process of research. Without due consideration of this process, the fate of 'ideas' remains opaque. 'Ideas' based on metaphor or analogical transfer were said to orient research in terms of the resources they mobilize and in terms of the investment opportunities they open up. Closure of this process is achieved through the active constructions of the laboratory, that is through negotiation and instrumental fabrication. Innovations are not the beginning, but the transient and temporary end-product of this process.

\section{Conclusion}

What, then, are the conclusions we can draw with respect to the metaphor theory of innovation? We have heard how invoking a metaphor or an analogy mobilizes a source-model (Harre) which serves to illuminate a new situation. Without doubt this is why ancient rhetoric, demagogy and more generally the art of persuasion have long made systematic use of analogy relations (17). Yet the invokation of a metaphor or of an analogy is not in itself a piece of 'scientific innovation'. Research products which are classified as scientific innovations include a crucial element of success: success in working out in the laboratory, success in being used by other scientists, success in convincing others that some research product is an 'innovation'. The metaphor-theory of innovation does not look at the fabrication and negotiation, at the construction and deconstruction which establishes and demolishes a research as a 'scientific innovation'. We have said that the metaphor account of innovation 
needs to be extended to include analogy in general. But it also needs to be restricted in its claim to account for scientific innovation. Reference to metaphor and analogy tells us something about the sources and consequences of problemshifts and about the circulation and transformation of selections in scientific - as well as everyday - practical reasoning. It suggests why scientists are intrigued by analogy-based 'ideas' which they qualify as 'solutions', and why they let their research be oriented by the 'opportunities' they provide. But reference to metaphor or analogy tells us nothing about whether the problemshifts will be, in Lakatos' terms (18), progressive or degenerative, whether they will be called a failure, or an innovation. Studies of metaphor and analogy in science have in mind only those similes and conceptual shifts which have made their way in the literature. The process of research production and reproduction is more complex than the equation of metaphor and innovation suggests.

\section{Notes and References}

1. This and the following examples drawn upon one year of observations done in 1976-1977 in a group of scientists working on plant protein generation at a research laboratory employing more than 300 scientists in Berkeley, $\mathrm{Ca}$., and on interviews done with members of other groups at the same laboratory. The laboratory is oriented toward basic and applied research in chemical, physical, microbiological, toxicological, technological and economic areas. Most of the scientists hold degrees in biochemistry and in one of the above areas. The plant-protein work observed most closely covered a variety of questions involving a series of disciplinary approaches, such as the generation and recovery of protein, its purification, explorations of its biological value and of the structure of protein particles, or questions of texture and of the use of protein additives. Reports, comments and citations are based upon my notes and upon tape recordings made during discussions and interviews. The preceding quote comes from a member of the plant protein group who told me what he had thought after the simile had been brought up. For more detailed discussions of the data and the methodology of the study see the monograph: K. Knorr, The Manufacture of Knowledge. Toward a Constructivist and Contextual Theory of Science, Pergamon, Oxford, 1980.

Needless to say, in depth studies such as the present do not constitute a solid basis for generalizations. The examples given can serve as no more than illustrations for the kind of experience in which the points that are made are grounded. Yet the issue at present may not be to arrive at 'statistically representative' results. The issue may be to use whatever limited basis we have.

2. For a summary of the metaphor-theory of innovation, see M. Black, Models and Metaphors, Cornell University Press, Ithaca, N. Y., 1962; D. A. Schon, Displacement 
of Concepts, Tavistock, London, 1963; For the distinction between metaphor and analogy see particularly M. Hesse, Models and Analogies in Science, University of Notre Dame Press, Notre Dame, IN, 1970. See also R. Harre, 'Models in Science', Phys. Educ. 13, 275-278 (1978). An overview over recent discussions of philosophical, cognitive and semantic aspects of metaphor is found in the 'Special Issue on Metaphor,' Critical Inquiry 5, (1978).

3. The example is cited in Hesse, op. cit., 1970, Note 2, e.g. p. 167.

4. In spite of numerous suggestions for definitions, the notion of similarity has been notoriously repugnant to precise explication. The attempt to define the resemblance between two objects in terms of the quantity of properties they have in common leads to the difficulty that on the level of comparative similarity almost any two things could count as common members of some broader kind. If a set theory definition is chosen which holds all members of a set to be more similar to one another than they are to other things outside the set, than Goodman's difficulty of imperfect community comes in. For example, all red round things, red wooden things, and round wooden things would meet the definition, yet we would not want to admit round dinner tables and red rubber balls as belonging to one kind. For a more extensive discussion of this see W. V. Quine, Ontological Relativity and Other Essays, Columbia University Press, New York, 1969, Chapter 5; or N. Goodman, The Structure of Appearance, Bobbs Merril, New York, 1966, 163-ff. According to Quine, similarity classifications are pervasive: The notions of induction, of causality, and of a disposition to react are all definable in terms of similarity classes. See Quine, op. cit., 1969, $125 \mathrm{ff}$. and $144 \mathrm{ff}$.

5. M. Hesse, The Structure of Scientific Inference, University of California Press, Berkeley, Ca., 1974, Chapter 1. Hesse approaches the problem of the relationship between theory and observation from the perspective of a logic of resemblance without requiring that we can ultimately say in what the primitive resemblance of properties of two objects consist.

'6. For a summary of what cognitive psychology has to say to the interaction between theroy and data in science see M. DeMey, 'The Interaction between Theory and Data in Science. A New Model for Perception Applied to Harvey's Discovery of the Circulation of the Blood', this volume.

7. For a general discussion of shifts of meaning and particularly of shifts in the degree of 'entrenchment' of terms used in primary recognition in our natural language see Hesse, op. cit., 1974, Note 5.14 ff. Similarity on Hesse's account is "primitive but at the same time complex since it comes in varying degrees and relates pairs of objects in respect of different property dimensions". See page 67.

8. A. Koestler, The Act of Creation, Pan Books, London, 1969.

9. For a discussion of what is involved in seeing something as something, and particularly, for the need to presuppose an institution of seeing cf. E. Gombrich, Art and Ilusion, Pantheon Books, New York, 1960. For pictorial representation and resemblance see also N. Goodman, Languages of Art, Bobbs-Merril, Indianapolis, 1968.

10. The notion of 'displacement of concepts' was introduced by Schon and used by Mulkay to refer to the transfer of ideas which comes about when scientists change their research network. Both Schon and Mulkay identify the notion of displacement of concepts with a metaphoric extension of ideas, although Mulkay's examples, 
if I understand them correctly, involve literal rather than figurative similarities. This is probably due to Schon's tendency to identify metaphor with analogy in general. Cf. Schon, op. cit., 1963, Note 2; and M. Mulkay, 'Conceptual Displacement and Migration in Science: A Prefatory Paper', Science Studies 4, 205-234 (1974).

11. W. Cooper, The Struggles of Albert Woods, Penguin Books, Harmondsworth, Middlesex, 1966, p. 229.

12. In this sense Small's classical definition of an interest as an 'unsatisfied capacity' fits the case. A. W. Small, General Sociology, Chicago-London, 1905, p. 433.

13. This suggestion comes from M. Callon, J. P. Courtial and W. Turner, Les actions concertees chimie macromoleculaire. Sociologique d'une agence de traduction, unpub. report of the Ecole Nationale Superieure des Mines, Centre de Sociologie de l'Innovation, Paris, 1979.

14. Cf. W. Cooper, op. cit., 1966, Note 11, p. 230. Albert Wood has the problem of creating an 'innovation' he has already announced in public, but not yet worked out. In the book it says: "Albert had two things against him; the first, that he could not lay himself open for something to strike a spark on him - he had got to strike a spark on it; the second, that his obsession could not take its natural course completion and perfection had got to be reached in a couple of months if not earlier."

15. Disregarding the question of whether unanimous acknowledgement of some scientific research result as an 'innovation' ever occurs.

16. According to the personal communication of members of a group which works at present in this area.

17. There are other elements not considered here which add to the popularity of analogy and metaphor in persuasive discourse, e.g. the pictorial element of referring to something of which one has a concrete picture in mind.

18. I. Lakatos, 'Criticism and the Methodology of Scientific Research Programmes' 